Article

\title{
Curing Behavior, Rheological, and Thermal Properties of DGEBA Modified with Synthesized BPA/PEG Hyperbranched Epoxy after Their Photo-Initiated Cationic Polymerization
}

\author{
Tossapol Boonlert-uthai ${ }^{1}$ (D) Kentaro Taki $^{2}(\mathbb{D})$ and Anongnat Somwangthanaroj ${ }^{1, *(D)}$ \\ 1 Department of Chemical Engineering, Faculty of Engineering, Chulalongkorn University, \\ Bangkok 10330, Thailand; tossapol.bu@gmail.com \\ 2 School of Mechanical Engineering, Kanazawa University, Kanazawa 920-1192, Japan; \\ taki@se.kanazawa-u.ac.jp \\ * Correspondence: anongnat.S@chula.ac.th; Tel.: +66-2218-6860
}

Received: 12 August 2020; Accepted: 21 September 2020; Published: 29 September 2020

check for updates

\begin{abstract}
This paper investigates the photo-initiated cationic polymerization of diglycidyl ether of bisphenol A (DGEBA) modified with bisphenol A (BPA)/polyethylene glycol (PEG) hyperbranched epoxy resin. The relationship between curing behavior, rheological, and thermal properties of the modified DGEBA is investigated using photo-differential scanning calorimetry (DSC) and photo-rheometer techniques. It is seen that the addition of the hyperbranched epoxy resin can increase UV conversion $\left(\alpha_{\mathrm{UV}}\right)$ and reduce gelation time $\left(t_{\mathrm{gel}}\right)$. After photo-initiation polymerization (dark reaction) occurred, a second exothermic peak in the DSC thermogram takes place: namely, the occurrence of curing reaction owing to the activated monomer (AM) mechanism. Consequently, the glass transition temperature decreased, and at the same time, UV intensity increased which was due to the molecular weight between crosslinking points $\left(M_{\mathrm{c}}\right)$. Furthermore, the radius of gyration $\left(R_{\mathrm{g}}\right)$ of the network segment is determined via small-angle X-ray scattering (SAXS). It is noted that the higher the $M_{c}$, the larger the radius of gyration proves to be, resulting in low glass transition temperature.
\end{abstract}

Keywords: hyperbranched epoxy; photo-polymerization; rheological property; thermal property

\section{Introduction}

In the electronics, coatings, and automotive industries, UV curing application is extensively used. This is because of the many advantages of UV curable resins, such as high reaction rate, good adhesion, curing at ambient temperature, and low energy consumption [1,2]. In addition, this single component, solvent free type of resin has high stability at any storage condition. Photo-initiated cationic polymerization is a curing reaction of the thermosetting materials, especially epoxy systems. Once a photoinitiator absorbs UV light, the photoinitiator is cleaved by UV light and changed into radicals and protonic acids or Brönsted acids. They can initiate cross-linking polymerization with a monomer. Polymer networks are finally formed. The photoinitiator used for the photo-initiated cationic polymerization is mostly onium salts, such as diaryliodonium salt and triarylsulfonium salt [3]. Crivello [3], one of the best photo-polymerization experts, proposed the overall mechanism of photolysis of a diaryliodonium salt $\left(\mathrm{Ar}_{2} \mathrm{I}^{+} \mathrm{MtX}-\mathrm{n}_{\mathrm{n}}^{-}\right.$and a monomer $(\mathrm{M})$, as described in Equations (1)-(4):

$$
\mathrm{Ar}_{2} \mathrm{I}^{+} \mathrm{MtXn}^{-} \stackrel{h v}{\longrightarrow}\left[\begin{array}{c}
\mathrm{ArI}^{+} \mathrm{MtXn}^{-}+\mathrm{Ar} \cdot \\
\mathrm{Ar}^{+} \mathrm{MtXn}{ }^{-}+\mathrm{ArI}
\end{array}\right]
$$




$$
\begin{gathered}
{\left[\begin{array}{c}
\mathrm{ArI}^{+} \mathrm{MtXn}^{-}+\mathrm{Ar} \cdot \\
\mathrm{Ar}^{+} \mathrm{MtXn}{ }^{-}+\mathrm{ArI}
\end{array}\right] \underset{\substack{\text { solvent or } \\
\text { monomer }}}{\mathrm{HMtX}_{\mathrm{n}}}} \\
\mathrm{HMtX}+\mathrm{M} \longrightarrow \mathrm{HM}^{+} \mathrm{MtX}_{\mathrm{n}}{ }^{-} \\
\mathrm{HM}^{+} \mathrm{MtX}^{-}+n \mathrm{M} \longrightarrow \mathrm{H}(\mathrm{M})_{n-1} \mathrm{M}^{+} \mathrm{MtX}_{\mathrm{n}}^{-}
\end{gathered}
$$

The photoinitiator bearing anions viz., $\mathrm{MtX}_{\mathrm{n}}^{-}$affects the polymerization rate of photoinitiated cationic polymerization. The order of $\mathrm{MtX}_{\mathrm{n}}^{-}$increasing polymerization rates is as follows: $\mathrm{SbF}_{6}^{-}>\left(\mathrm{C}_{6} \mathrm{~F}_{6}\right)_{4} \mathrm{~B}^{-}>\mathrm{AsF}_{6}^{-}>\mathrm{PF}_{6}^{-}>\mathrm{BF}_{6}^{-}>\mathrm{ClO}_{4}^{-}$[1,3-5]. In the presence of alcohol, the ring-opening cationic polymerization of epoxy takes place with two different mechanisms: the activated chain end (ACE) and the activated monomer (AM) mechanisms, as shown in Figure 1 [6]. The ACE mechanism is a general reaction for the ring cationic polymerization of the epoxy system. First, the acid initiator reacts with an epoxy monomer. Then, there is the formation of an activated monomer or propagating center. Next, the activated monomer reacts with monoalcohol by transfer reaction, resulting in the formation of a dead end. Concurrently, the dead-end ( $\mathrm{OH}$ group) continues to react with the activated monomer to produce a protonated ether and forms a new hydroxyl-terminated extended molecule by deprotonation by the epoxide monomer. As a result, the growing polymer chain was terminated but it can continue to react with the activated monomer. Repetition of this mechanism regenerates a hydroxyl-terminated chain that continues the termination and transfers reactions. Therefore, each time the $\mathrm{OH}$ group reacts, another $\mathrm{OH}$ group is produced; and this condition is called the AM mechanism. The rates of ACE and AM mechanisms [7] are shown in Equations (5) and (6), respectively:

$$
\begin{gathered}
\mathrm{R}_{\mathrm{ACE}}=\mathrm{k}_{\mathrm{ACE}}\left[\mathrm{M}^{+}\right][\mathrm{M}] \\
\mathrm{R}_{\mathrm{AM}}=\mathrm{k}_{\mathrm{AM}}\left[\mathrm{M}^{+}\right][\mathrm{ROH}]
\end{gathered}
$$

where $\mathrm{k}_{\mathrm{AEC}}$ is the rate constant of ACE mechanism, $\mathrm{k}_{\mathrm{AM}}$ is the rate constant of AM mechanism, $[\mathrm{M}]$ is a concentration of monomer $\mathrm{M},\left[\mathrm{M}^{+}\right]$is a concentration of activated monomer $\mathrm{M}^{+}$, and $[\mathrm{ROH}]$ is a concentration of alcohol $\mathrm{ROH}$.
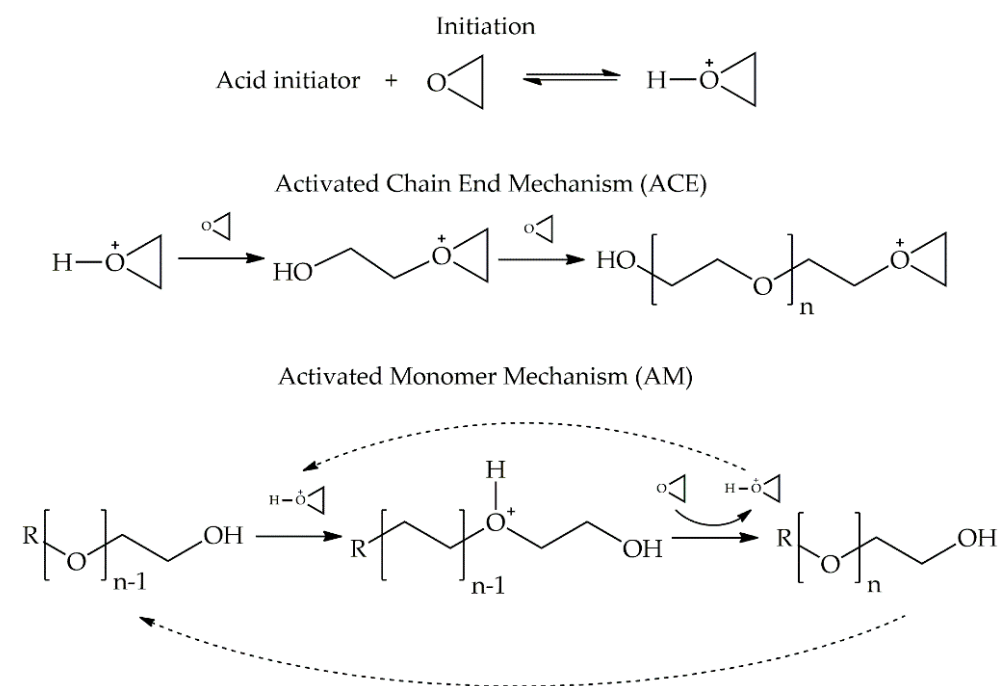

Figure 1. The mechanisms of the ring-opening cationic polymerization of epoxy in the presence of alcohol: the activated chain end (ACE) and the activated monomer (AM) mechanisms [6].

In a complex area or large thickness of a sample, UV curing reaction may be incomplete because UV light cannot penetrate into deep layers [8]. During curing reaction, the glass transition temperature $\left(T_{\mathrm{g}}\right)$ of a sample increases [9] until it forms a gel. If the temperature is not higher than the glass transition temperature at the gel point $\left(T_{\mathrm{g}, \text { gel }}\right)$, vitrification occurs, resulting in the restriction of the 
curing reaction $[1,10]$. Therefore, the reaction has to be performed at a suitable temperature: at a higher temperature. Higher UV intensity also needs to be applied [11] in order to accelerate the reaction rate and to complete the curing reaction [12,13].

The commercial epoxy thermoset DGEBA is widely used because it has high thermal and mechanical properties, high chemical resistance, and low shrinkage. Yet, DGEBA is known to have some inherent adverse properties: brittleness and low toughness $[1,14,15]$. Nevertheless, a number of researchers have been engaged in developing properties that have toughening agents or plasticizers, especially PEG, to improve the low impact resistance of DGEBA by decreasing $T_{\mathrm{g}}$ [16-19]. Researchers have also studied the mechanisms that affect the final properties of the epoxy thermoset.

In recent years, hyperbranched polymers have been used for industrial-scale productions and applications such as additives and resins for high-performance materials, rheology modifiers, diluents, and crosslinkers [20]. This is because hyperbranched polymers are easy to synthesize, and have low viscosity, high solubility, as well as a large number of desired end functional groups. In our previous research [21], the hyperbranched epoxy resins, consisting of BPA and PEG reactants together with pentaerythritol (PE) as a branching point, have been successfully synthesized and characterized, as shown in Figure 2. Hyperbranched epoxy resins have gained strength from the BPA structure and flexibility from the PEG structure. Thermally cured hyperbranched epoxy is highly resistant and stable because it does not have a melting point that is the defect of the thermosetting materials $[19,22]$.

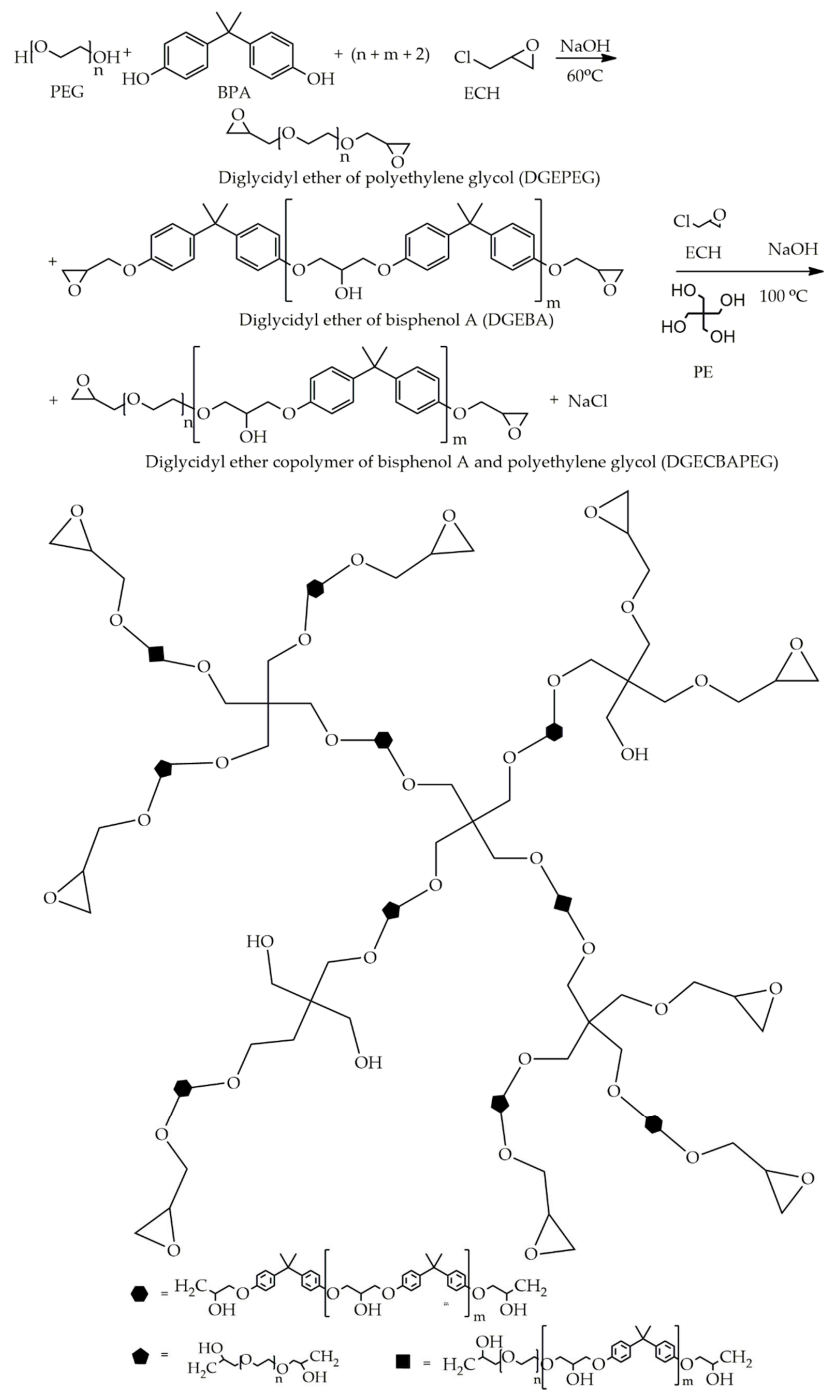

Figure 2. The synthesis and possible structure of bisphenol A/polyethylene glycol (BPA/PEG) hyperbranched epoxy resin [21]. 
This research aims to improve UV curing reaction and the inherent adverse properties of DGEBA. The study focuses on the relationship of curing behavior, rheological, and thermal properties of DGEBA modified with hyperbranched epoxy resin through photo-initiated cationic polymerization. The curing reaction and thermal properties have been investigated via photo-DSC and are seen to relate to the rheological properties using a photo-rheometer. The radius of gyration of the network segment has been evaluated using the small-angle X-ray scattering (SAXS) technique to examine the relationship among them.

\section{Materials and Methods}

\subsection{Materials}

DGEBA, having an epoxy equivalent weight (EEW) of $170.21 \mathrm{~g} \mathrm{eq}^{-1}$, (Sigma-Aldrich, St. Louis, MO, USA) was used as the main base of epoxy resin in the formulated mixture. Hyperbranched epoxy resin was synthesized and characterized via FTIR and NMR techniques. The results are shown in Figures S1 and S2, respectively. The chemical for the synthesis: BPA (Tokyo Chemical Industry Co., Ltd., Tokyo, Japan) was used as an aromatic monomer, and was purified via recrystallization using toluene before use. PEG400, Mw $=400 \mathrm{~g} / \mathrm{mol}$, (Sigma-Aldrich, St. Louis, MO, USA) was used as an aliphatic monomer. Epichlorohydrin (ECH), (Tokyo Chemical Industry Co., Ltd., Tokyo, Japan) was used as an epoxidation reagent. PE (Tokyo Chemical Industry Co., Ltd., Tokyo, Japan) was used as a branch generating unit and was recrystallized with ethanol before use. Sodium hydroxide $(\mathrm{NaOH})$ as a base catalyst and sodium chloride $(\mathrm{NaCl})$ were obtained from Ajax Finechem, Sydney, Australia. Hydrobromic acid (HBr), acetic acid, potassium acid phthalate, methyl violet, and chlorobenzene (Tokyo Chemical Industry Co., Ltd., Tokyo, Japan) were used to determine the epoxy equivalent weight (EEW) following the standard test methods (ASTM D 1652) [23]. Triarylsulfonium hexafluorophosphate salts (Sigma-Aldrich, St. Louis, MO, USA) were used as a photoinitiator.

\subsection{Synthesis of Hyperbranched Epoxy Resin}

The hyperbranched epoxy resins were synthesized by the $A_{2}+B_{4}$ polycondensation reactions [6] using PEG400 and BPA as $\mathrm{A}_{2}$ monomers and PE as $\mathrm{B}_{4}$ monomer. The amount of $\mathrm{B}_{4}$ monomer was $10 \mathrm{wt} \%$ of $\mathrm{A}_{2}$ monomer's content and the mass ratio of BPA to PEG400 was 90:10 (HBE10P). The molar ratio of $\mathrm{ECH}$ to $\mathrm{A}_{2}$ monomers was fixed at 2:1. First, PE, BPA, and $\mathrm{ECH}$ were mixed in a two-necked RB flask installed with a condenser and dropping funnel at $60^{\circ} \mathrm{C} .5 \mathrm{~N}$ aqueous $\mathrm{NaOH}$ solution was slowly dripped into the mixture for $30 \mathrm{~min}$ and the reaction temperature was set at $110^{\circ} \mathrm{C}$ for $4 \mathrm{~h}$ when the desired time was completed, the reaction was terminated by immediately quenching the mixture. The mixture was then poured into a separation funnel in order to separate the aqueous layer (the residual reactants) from the organic layer. The organic layer was purified by washing with $15 \mathrm{wt} \%$ $\mathrm{NaCl}$ solution followed by distilled water until the washer's $\mathrm{pH}$ was 8-9. Finally, the organic solution was dried in a vacuum oven at $70^{\circ} \mathrm{C}$ until the mass of the sample was constant and viscous transparent liquid was observed.

\subsection{Preparation of Epoxy Mixtures}

There are two systems of epoxy mixtures: the DGEBA system (100 wt \% of DGEBA) and the D90H10 system (90 wt \% of DGEBA and $10 \mathrm{wt} \%$ of HBE10P, EEW $=564 \mathrm{~g} \mathrm{eq}^{-1}$ ). The weight of both resins was $10 \mathrm{~g}$. As for the D90H10 system, DGEBA and synthesized HBE10P resins were homogenously blended for $10 \mathrm{~min}$ at $40^{\circ} \mathrm{C}$. After blending, $0.5 \mathrm{~g}$ triarylsulfonium hexafluorophosphate salts ( $5 \mathrm{wt} \%$ of resin) were added to the resins and the mixture was mechanically stirred at room temperature for $10 \mathrm{~min}$. In Table 1 , the code for curing condition is IxxTyytzz where $I$ is UV intensity $\left(\mathrm{xx}=10,20,30,40\right.$ and $\left.50 \mathrm{~mW} / \mathrm{cm}^{2}\right), T$ is temperature $\left(\mathrm{yy}=80^{\circ} \mathrm{C}\right)$ and $t$ is irradiation time $(\mathrm{zz}=60 \mathrm{~s})$. For example, I10T80t60 code is the condition using UV intensity of $10 \mathrm{~mW} / \mathrm{cm}^{2}, T=80^{\circ} \mathrm{C}$, and $t=60 \mathrm{~s}$. 
Table 1. The mixture of epoxy systems.

\begin{tabular}{lcccccc}
\hline \multirow{2}{*}{ System } & \multirow{2}{*}{ EEW $\left(\mathbf{g ~ e q}^{-\mathbf{1}}\right)$} & \multicolumn{2}{c}{ DGEBA Resin } & \multicolumn{2}{c}{ HBE10P Resin } & Photoinitiator \\
\cline { 3 - 7 } & & wt $\%$ & Mass (g) & wt \% & Mass (g) & Mass (g) \\
\hline DGEBA & 170.21 & 100 & 10.0 & - & - & 0.5 \\
\hline D90H10 & 182.98 & 90 & 9.0 & 10 & 1.0 & 0.5 \\
\hline
\end{tabular}

The mixture EEW was calculated, as expressed in Equation (7):

$$
\text { EEW mixture }=\frac{\text { Total Wt }}{\frac{\mathrm{Wt}_{a}}{\mathrm{EEW}_{a}}+\frac{\mathrm{Wt}_{b}}{\mathrm{EEW}_{b}}}
$$

\subsection{Curing Behavior and Thermal Property}

Both curing behavior and thermal properties of the epoxy systems were investigated via photo-DSC (PerkinElmer: DSC8500, Waltham, MA, USA), as shown in Figure S6a, under nitrogen atmosphere: three times for each system. The UV source and high-pressure mercury lamp were from Omicure Series2000 (Excelitas Technologies, Waltham, MA, USA). For the purpose of calibrating UV intensity, a carbon black plate was used in the sample cell. The intensity was determined through the relationship between the power of UV light and UV energy. This UV energy is generated through the absorption of UV light by the carbon black plate. The uncured samples $(8.0 \pm 0.2 \mathrm{mg})$ were placed in aluminum pans having quartz covers and put under isothermal condition for $1 \mathrm{~min}$ before and $3 \mathrm{~min}$ after UV exposure. For the first scanning, UV curing was performed at $T=80^{\circ} \mathrm{C}$ for $1 \mathrm{~min}$ followed by UV irradiation of $10,20,30,40$, and $50 \mathrm{~mW} / \mathrm{cm}^{2}$ for $1 \mathrm{~min}$. After UV irradiation, the dark reaction proceeded under isothermal condition $\left(80^{\circ} \mathrm{C}\right)$ for $3 \mathrm{~min}$. The residual heat of reaction of the cured samples was measured via a second scan in the range of $30-180^{\circ} \mathrm{C}$, along with a heating rate of $10^{\circ} \mathrm{C} / \mathrm{min}$ to inspect the heat profile. Lastly, the second protocol was repeated to determine the glass transition temperature $\left(T_{\mathrm{g}}\right)$ of the cured samples. Conversion $(\alpha)$ or degree of cure of the cured samples was evaluated, as in Equation (8):

$$
\alpha=\frac{\Delta H_{1}}{\Delta H_{\text {total }}} ; \quad \Delta H_{\text {total }}=\Delta H_{1}+\Delta H_{\text {res }}
$$

where $\Delta H_{\text {total }}$ is the total heat of reaction, $\Delta H_{1}$ is the heat of reaction in the first scan, and $\Delta H_{\text {res }}$ is the residual heat of reaction in the second scan.

\subsection{Rheological Property}

The rheological property of the epoxy systems was determined by the photo-rheometer MCR-302WEPS (Anton-Paar, Graz, Austria), as shown in Figure S6b. The UV source and high-pressure mercury lamp were from Omicure Series 2000 (Excelitas Technologies). The rheological properties of the uncured samples were evaluated within the linear viscoelastic region using a parallel plate (PP12-Dispo, $\mathrm{d}=12 \mathrm{~mm}$ ) with a gap between parallel plates of $0.1 \mathrm{~mm}$, frequency of $10 \mathrm{~Hz}$, strain of $0.1 \%$, and isothermal temperature of $80^{\circ} \mathrm{C}$. Each system has been evaluated three times to confirm the repeatability of results. To maintain initial viscosity and initial modulus of the uncured samples, they were held under isothermal condition for $1 \mathrm{~min}$ before the curing reaction took place, as shown in Figure 3. The UV curing experiments were performed applying five UV intensities i.e., 10, 20, 30, 40, and $50 \mathrm{~mW} / \mathrm{cm}^{2}$ for $1 \mathrm{~min}$. 

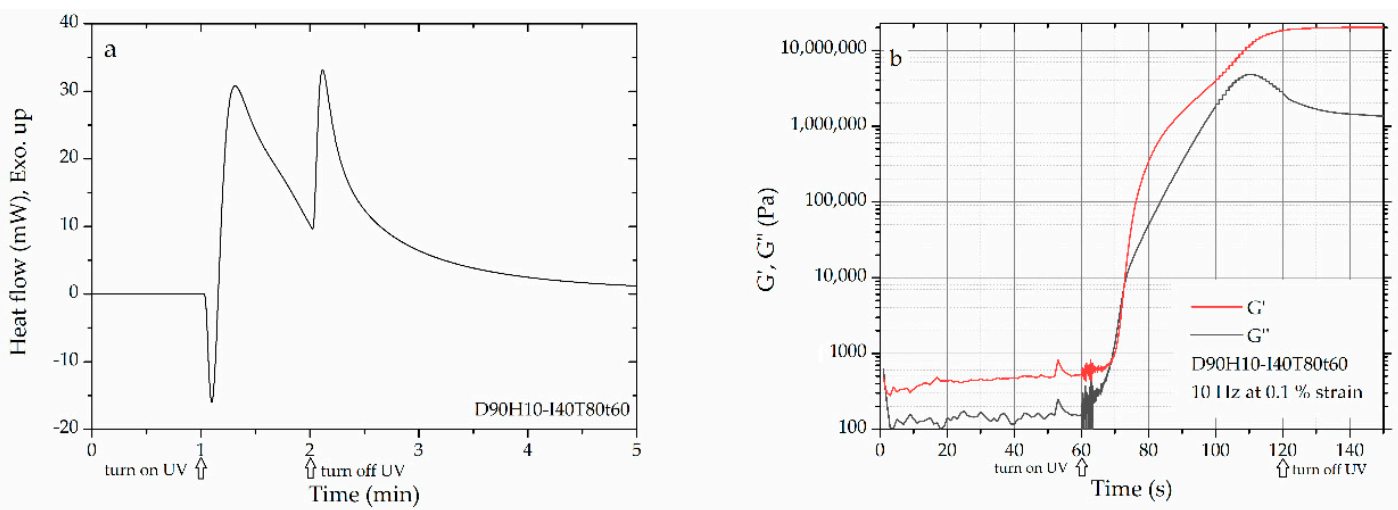

Figure 3. The representative data of (a) differential scanning calorimetry (DSC) and (b) rheological measurements.

\subsection{Radius of Gyration of the Network Segment}

The radius of gyration was investigated via small-angle X-ray scattering (SAXS) technique (Nano Viewer RA-MICRO7HFM, Rigaku, Tokyo, Japan). The wavelength of the incident X-ray (CuK $\alpha$ ) was $0.154 \mathrm{~nm}$ and the camera length, the sample-to-detector distance, was $700 \mathrm{~mm}$. The range of the scattering vector length (q) was $0.014-0.355 \mathrm{~nm}^{-1}$. The cured samples, DGEBA and D90H10 systems, obtained from photo-DSC experiments, were measured under isothermal condition $\left(25^{\circ} \mathrm{C}\right)$. The size of the imaging plate (IP) detector was $125 \times 125 \mathrm{~mm}$.

The radius of gyration $\left(R_{\mathrm{g}}\right)$ indicates a nanodomain dispersed in the epoxy matrix, as shown in Figure 4 and was evaluated by the Zimm plot (1/I vs $\left.\mathrm{q}^{2}\right)$. The Ornstein-Zernike model [24] was assumed for the q-dependence of the scattering intensity $I(q)$, as in Equations (9) and (10):

$$
\begin{gathered}
I(\mathrm{q})=\frac{I_{0}}{1+\xi^{2} \mathrm{q}^{2}} \\
\frac{1}{I}=\frac{1}{I_{0}}+\frac{\xi^{2} \mathrm{q}^{2}}{I_{0}}
\end{gathered}
$$

where $\xi$ is the correlation length and $I_{0}$ is the absolute intensity. A plot of $1 / I$ vs. $\mathrm{q}^{2}$ (Equation (10)) produces $1 / I_{0}$ (intercept) and $\xi^{2} / I_{0}$ (slope). At low $q$, the radius of gyration was evaluated, as shown in Equation (11):

$$
\mathrm{R}_{\mathrm{g}}=\sqrt{3} \xi
$$

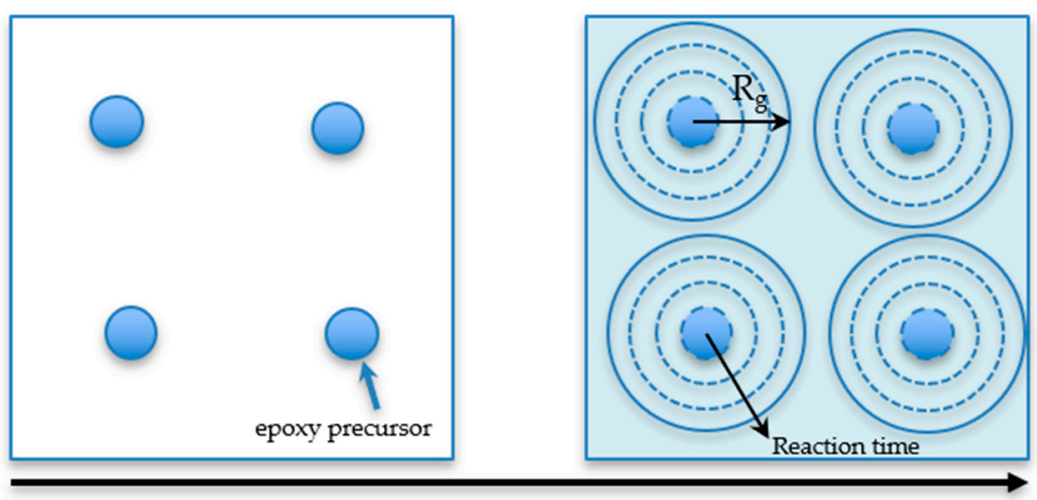

Reaction time

Figure 4. The transition of epoxy nanodomains through reaction time. 


\subsection{Molecular Weight Between Crosslinking Points}

The molecular weight between crosslinking points $\left(M_{\mathrm{c}}\right)$ is simply the average molecular weight of the monomer $\left(M_{\mathrm{av}}\right)$ divided by the number of cross-links per molecule $(\mathrm{c})$, as in Equation (12):

$$
M_{\mathrm{c}}=\frac{M_{a v}}{\mathrm{c}}
$$

Even though it is difficult to evaluate the number of cross-links per molecule, there is a relationship between the network structure and gelation [25]. The modulus of the entangled polymer network can be approximated, as a simple sum, as shown in Equation (13):

$$
\mathrm{G} \cong \mathrm{G}_{\mathrm{x}}+\mathrm{G}_{\mathrm{e}} \approx \rho \mathrm{RT}\left(\frac{1}{M_{\mathrm{x}}}+\frac{1}{M_{\mathrm{e}}}\right)
$$

where $G_{x}$ is the modulus of all classic models, $G_{e}$ is the rubbery plateau modulus of high molar mass polymer, $\rho$ is the density of the cured sample, $\mathrm{R}$ is the gas constant $\left(8.314 \mathrm{~m}^{3} \mathrm{~Pa} \mathrm{~K}^{-1} \mathrm{~mol}^{-1}\right)$, $T$ is temperature $(\mathrm{K}), M_{\mathrm{x}}$ is the apparent molar mass, and $M_{\mathrm{e}}$ is the entanglement molar mass. At the gel point, entanglement effects become negligible when compared with the effects of covalent cross-links, such as high viscosity and high storage modulus; therefore, the $\mathrm{G}^{\prime}$ gel can be expressed, as in Equation (14):

$$
\mathrm{G}_{\text {gel }}^{\prime} \approx \frac{\rho \mathrm{RT}}{\mathrm{M}_{\mathrm{C}}}
$$

where $G^{\prime}$ gel is the storage modulus at the gel point and the $\rho$ of each sample was determined by the density kit MS-DNY-54 (Mettler Toledo, Greifensee, Switzerland), as presented in Table S1.

\section{Results and Discussion}

\subsection{Curing Behavior and Rheological Property at Various Photo-Curing Conditions}

The curing behavior and rheological property of the DGEBA and D90H10 systems, using triarylsulfonium hexafluorophosphate salts acting as photoinitiator, were investigated via photo-DSC and photo-rheometer, respectively. These properties were studied by varying UV intensity $(10,20,30$, 40 , and $50 \mathrm{~mW} \mathrm{~cm}^{-2}$ ), having an irradiation time of $60 \mathrm{~s}$ and temperature of $80^{\circ} \mathrm{C}$. Photocuring was performed at $80^{\circ} \mathrm{C}$ to avoid vitrification during the reaction and to follow the real process of the hard disk drive production wherein photocuring was performed at high temperature.

In terms of the rheological property of epoxy resin, an important parameter is gelation time $\left(t_{\text {gel }}\right)$. Gelation time is the time of the curing reaction for all monomers approaching maximum molecular weight between crosslinking points. As shown in Figures S3 and S4, the $t_{\text {gel }}$ can be found at the crossover of storage modulus $\left(G^{\prime}\right)$ and loss modulus $\left(G^{\prime \prime}\right)$ : gelation point. As tabulated in Table 2, it is clear that when UV intensity increased, the $t_{\text {gel }}$ of both systems decreased because of the high concentration of the activated photoinitiator, generating a high reaction rate. As shown in Figure 5a,b, the photo-rheological properties were seen to be complementary to the UV conversion $\left(\alpha_{U V}\right)$ from DSC's heating profile. Thus, higher UV conversion of epoxy with low $t_{\text {gel }}$ was observed and the increase in UV intensity was found to accelerate curing reaction. However, the conversion and cure rate of the D90H10 system proved to be higher than that of the DGEBA system because of the ball-bearing effect [26-28] and the branching of the hyperbranched structure, resulting in more mobility and more probability of reaction, as illustrated in Figure 6. Because of the increase and influence of the $\mathrm{OH}$ group in the system, there was a greater increase in the AM mechanism. 
Table 2. The properties of DGEBA and D90H10 systems at various UV intensity.

\begin{tabular}{|c|c|c|c|c|c|c|c|c|}
\hline \multirow[b]{2}{*}{ UV Intensity $\left(\mathrm{mW} / \mathrm{cm}^{2}\right)$} & \multicolumn{4}{|c|}{ Photo-Rheometer } & \multicolumn{3}{|c|}{ Photo DSC } & \multirow{2}{*}{$\begin{array}{c}\text { SAXS } \\
\mathrm{R}_{\mathrm{g}}(\mathrm{nm})\end{array}$} \\
\hline & $t_{\text {gel }}(s)$ & $\mathrm{G}_{\mathrm{gel}}^{\prime}(\mathrm{Pa})$ & $\mathrm{M}_{\mathrm{c}}\left(\mathrm{g} \mathrm{mol}^{-1}\right)$ & $\begin{array}{l}\text { Number of } \\
\text { Cross-Links Per } \\
\text { Molecule }\end{array}$ & $\alpha_{U V}$ & $\alpha$ & $\mathrm{T}_{\mathrm{g}}\left({ }^{\circ} \mathrm{C}\right)$ & \\
\hline 10 & $41.0 \pm 0.3$ & $2410 \pm 10$ & $1,028,532 \pm 245$ & $0.0003 \pm 1 \times 10^{-6}$ & $0.23 \pm 0.01$ & $0.90 \pm 0.01$ & $140.15 \pm 0.35$ & $13.42 \pm 0.14$ \\
\hline 20 & $31.6 \pm 0.3$ & $5025 \pm 30$ & $492,469 \pm 141$ & $0.0007 \pm 3 \times 10^{-6}$ & $0.25 \pm 0.01$ & $0.95 \pm 0.01$ & $120.72 \pm 0.57$ & $8.90 \pm 0.00$ \\
\hline 30 & $23.8 \pm 0.3$ & $4080 \pm 30$ & $608,043 \pm 345$ & $0.0006 \pm 4 \times 10^{-6}$ & $0.23 \pm 0.01$ & $0.95 \pm 0.00$ & $114.22 \pm 0.32$ & $6.67 \pm 0.01$ \\
\hline \multicolumn{9}{|l|}{ D90H10 } \\
\hline 10 & $22.3 \pm 0.2$ & $2643 \pm 50$ & $942,497 \pm 10$ & $0.0004 \pm 8 \times 10^{-6}$ & $0.56 \pm 0.01$ & $0.98 \pm 0.01$ & $132.70 \pm 0.72$ & $8.39 \pm 0.00$ \\
\hline 20 & $18.8 \pm 0.2$ & $1897 \pm 6$ & $1,311,499 \pm 7$ & $0.0003 \pm 9 \times 10^{-7}$ & $0.54 \pm 0.01$ & $0.99 \pm 0.00$ & $121.41 \pm 0.49$ & $9.06 \pm 0.00$ \\
\hline 30 & $11.4 \pm 0.4$ & $1880 \pm 10$ & $1,325,515 \pm 6$ & $0.0003 \pm 2 \times 10^{-6}$ & $0.69 \pm 0.01$ & $0.99 \pm 0.00$ & $102.93 \pm 0.68$ & $18.74 \pm 0.65$ \\
\hline 40 & $12.3 \pm 0.2$ & $7050 \pm 50$ & $354,106 \pm 2$ & $0.0011 \pm 8 \times 10^{-6}$ & $0.45 \pm 0.01$ & $1.00 \pm 0.00$ & $103.89 \pm 0.38$ & $10.82 \pm 0.00$ \\
\hline 50 & $12.0 \pm 0.2$ & $9160 \pm 20$ & $270,073 \pm 90$ & $0.0014 \pm 2 \times 10^{-6}$ & $0.69 \pm 0.01$ & $1.00 \pm 0.00$ & $107.59 \pm 0.80$ & $8.77 \pm 0.00$ \\
\hline
\end{tabular}
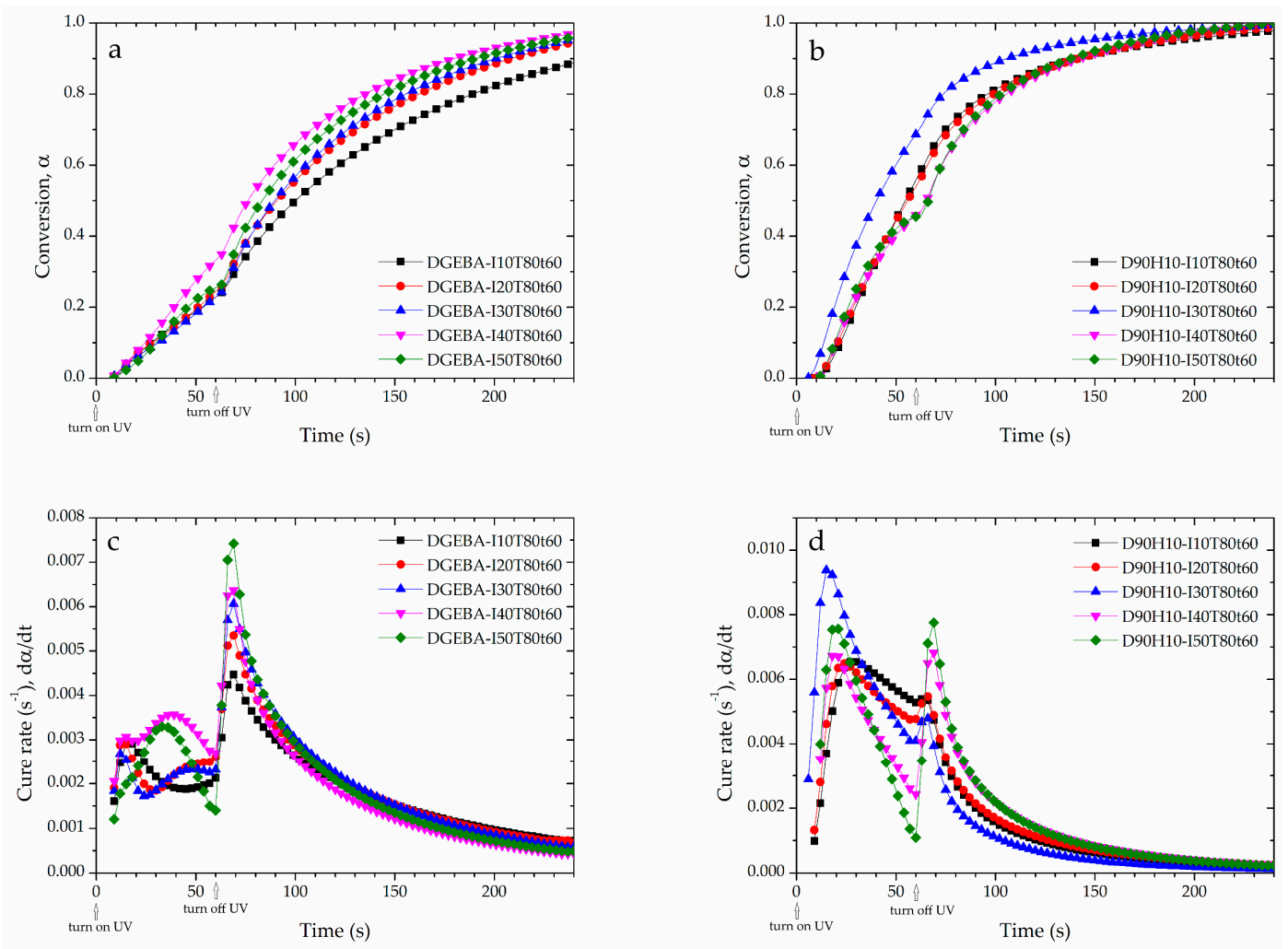

Figure 5. Conversion of (a) DGEBA and (b) D90H10, and cure rate of (c) DGEBA and (d) D90H10 with various $\mathrm{UV}$ intensity, the temperature of $80^{\circ} \mathrm{C}$ and irradiation time of $60 \mathrm{~s}$.

After being exposed to UV curing, the behavior of the DGEBA and D90H10 systems were not the same. This study used the molecular weight between crosslinking points $\left(M_{\mathrm{c}}\right)$ in order to explain the curing reaction, which was calculated, as in Equation (14). As shown in Table 2, with regards to the DGEBA system, when UV intensity increased, $M_{c}$ decreased. This decrease occurred because of the activated photoinitiator molecules, which gave rise to more protonated epoxide molecules. It was found, therefore, that the protonated epoxide chains reacted too fast, resulting in short-chain or low $\mathrm{M}_{\mathrm{c}}$, as illustrated in Figure 7. As shown in Figure $5 \mathrm{c}$, considering the cure rate $(\mathrm{d} \alpha / \mathrm{dt})$, there were double peaks of the cure rate profile during the UV curing. The second peak dominated the first peak when UV intensity was more than $30 \mathrm{~mW} / \mathrm{cm}^{2}$. The first peak depicts the formation of a network structure at the gel point; the second peak depicts the reaction of the activated molecules trapped in the network structure having high storage modulus at gelation time $\left(\mathrm{G}^{\prime}\right.$ gel $)$, as shown in Table 2 . When the systems were exposed to UV intensity of $10-30 \mathrm{~mW} / \mathrm{cm}^{2}$, the first peak was observed. However, when UV intensity increased from $30-50 \mathrm{~mW} / \mathrm{cm}^{2}$, the second peak predominated over the first peak. This 
result was due to the high concentration of the activated photoinitiator, which accelerated the UV curing reaction.

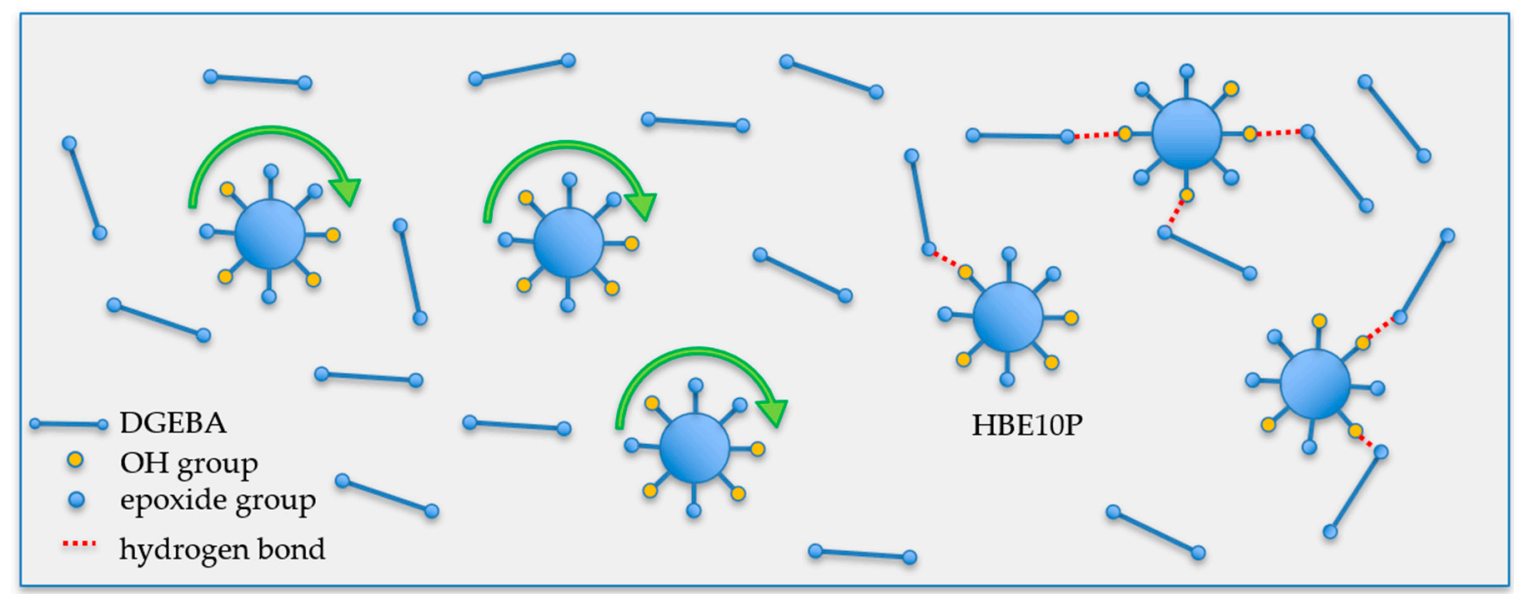

Figure 6. The effects of ball-bearing, globular and non-entanglement structure, and hydrogen bonds on the epoxy system.

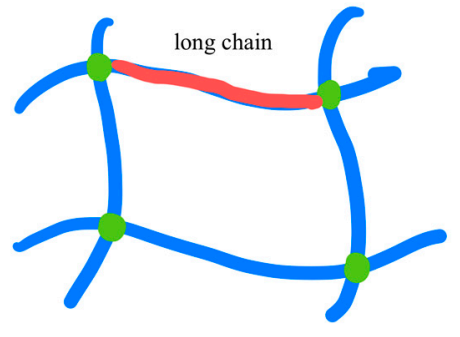

Low UV intensity

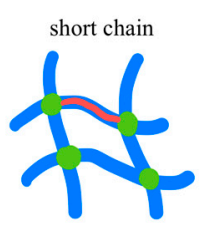

High UV intensity

Figure 7. Effect of UV intensity on formation of network structure through photo-cationic polymerization.

As regards the D90H10 system, the curing behavior and other properties were different from those of the DGEBA system. When UV intensity was raised to $30 \mathrm{~mW} / \mathrm{cm}^{2}, M_{\mathrm{c}}$ increased because of the hyperbranched structure and high molecular weight of the HBE10P resin. The increase in activated photoinitiator molecules and $\mathrm{OH}$ groups promoted more protonated epoxide molecules in HBE10P and more long chains because of the AM mechanism which in turn created large molecules between the crosslinking points. However, this occurrence was reversed when UV intensity increased from 30 to $50 \mathrm{~mW} / \mathrm{cm}^{2}$; thus, molecular weight between the crosslinking points greatly decreased. When excessive UV intensity is applied, the curing reaction is dependent on the DGEBA resin because the reactivity of DGEBA resin is much higher than that of the HBE10P resin whose UV conversion proved to be extremely low. Besides, it was noted that the excessive amount of activated photoinitiator molecules and protonated epoxide molecules resulted in very low $M_{\mathrm{c}}$. It was also clear that the cure rate slightly decreased and gelation time increased. This increase can be denoted by the high storage modulus at the gel point $\left(\mathrm{G}^{\prime}\right.$ gel $)$, which induced low mobility and low cure rate during the UV reactions. Finally, the D90H10 system proved to have a higher number of cross-links per molecule (c) than the DGEBA system. This outcome was due to the presence of the dangling HBE10P chains in the network structure which can react when in contact with an activated monomer, as depicted in Figure 8. 

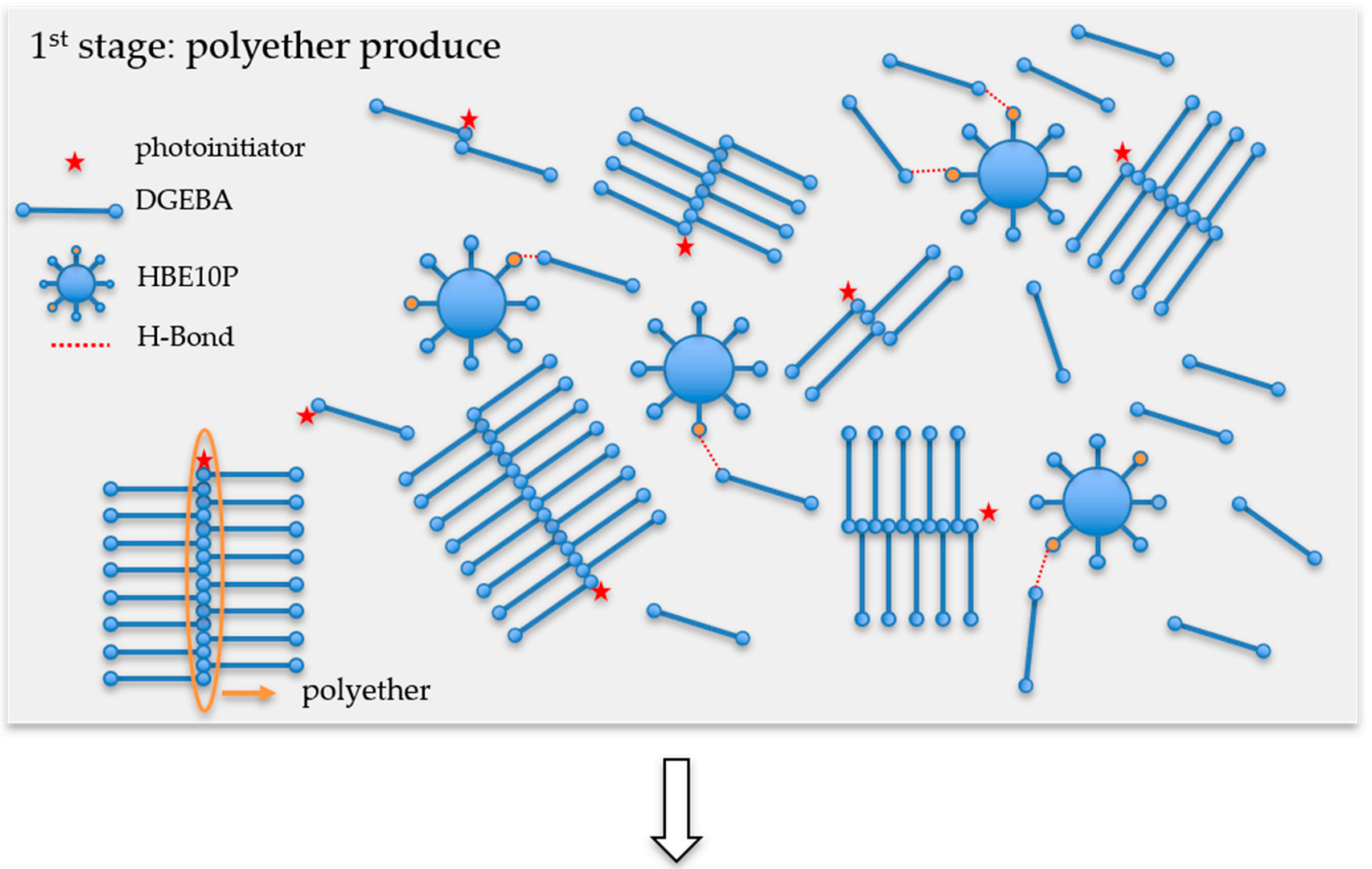

$2^{\text {nd }}$ stage: chain entanglement $\& 3^{\text {rd }}$ stage: crosslink \& network formation

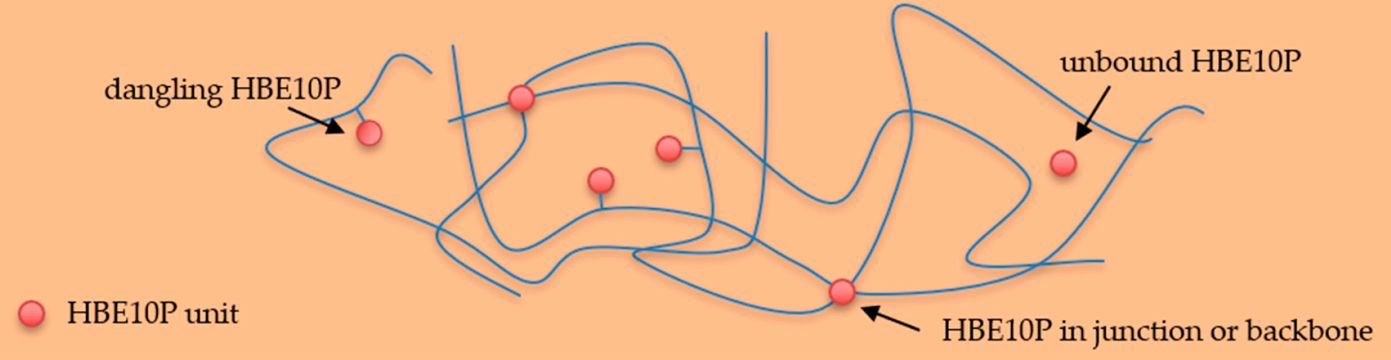

Figure 8. Scheme of UV curing reaction for DGEBA and HBE10P resins.

As shown in Figure $5 c, d$, it is seen that there were double peaks in the cure rate profile of both systems: UV and dark curing. The first peak is the UV curing and the second peak is the dark curing (after shutting UV light off). Because of the presence of hydroxyl group in the DGEBA and HBE10P resins, such phenomena can be explained in that there are two propagation mechanisms of the ring-opening cationic polymerization of epoxy in the presence of the hydroxyl group: ACE and AM mechanisms [6]. During UV reaction, the ACE mechanism predominates until the reaction surpasses the maximum rate. Subsequently, the AM mechanism predominates because of the concentration of the hydroxyl group, which is larger than that of the initiator $\left[I^{+}\right]$. After shutting off UV intensity (no generation of initiator), dark reaction follows the AM mechanism which is the chain transfer reaction, resulting in an activated monomer and the consumption of the $\mathrm{OH}$ group to produce another $\mathrm{OH}$ group. These reactions release heat. Thereby, the exothermic heat was observed via photo-DSC, culminating in a peak in the dark curing period. Moreover, the second peak at high UV intensity was seen to be higher than the second peak at low UV intensity, because of greater initiator concentration.

\subsection{The Thermal Properties and Radius of Gyration of the Cured Samples at Various Curing Conditions}

Glass transition temperature $\left(T_{\mathrm{g}}\right)$ is usually used as a parameter to identify thermal stability during use in any application. For example, the operating temperature in a hard disk drive (HDD) is 
between 25 and $80^{\circ} \mathrm{C}$. Therefore, $T_{\mathrm{g}}$ for any part in the HDD must not be in the range of the operating temperature. In Figure 9 and Table 2, the glass transition temperature for all samples is tabulated. When UV intensity increased, the $T_{\mathrm{g}}$ of the DGEBA and D90H10 systems decreased. However, the $T_{\mathrm{g}}$ of the D90H10 system was found to be lower than that of the DGEBA system because of the internal plasticizer effect of PEG's structure in the HBE10P resin, in which there were ether groups along with the free volume of the hyperbranched structure [21,29-33]. As for the epoxy system, the glass transition temperature generally increases when UV intensity, irradiation time, and temperature increase [34,35]. Besides, both the radius of gyration $\left(R_{\mathrm{g}}\right)$ and the distance from the center of the network section in the samples were investigated in order to describe and confirm this occurrence. In Figure S5, the light scattering profiles of all samples measured via SAXS are shown. Subsequently, the $R_{\mathrm{g}}$ of the network segment was evaluated by the Zimm plot (1/I vs. $\left.\mathrm{q}^{2}\right)$, as depicted in Figure 10. In Table S2, the results of the calculation are tabulated.
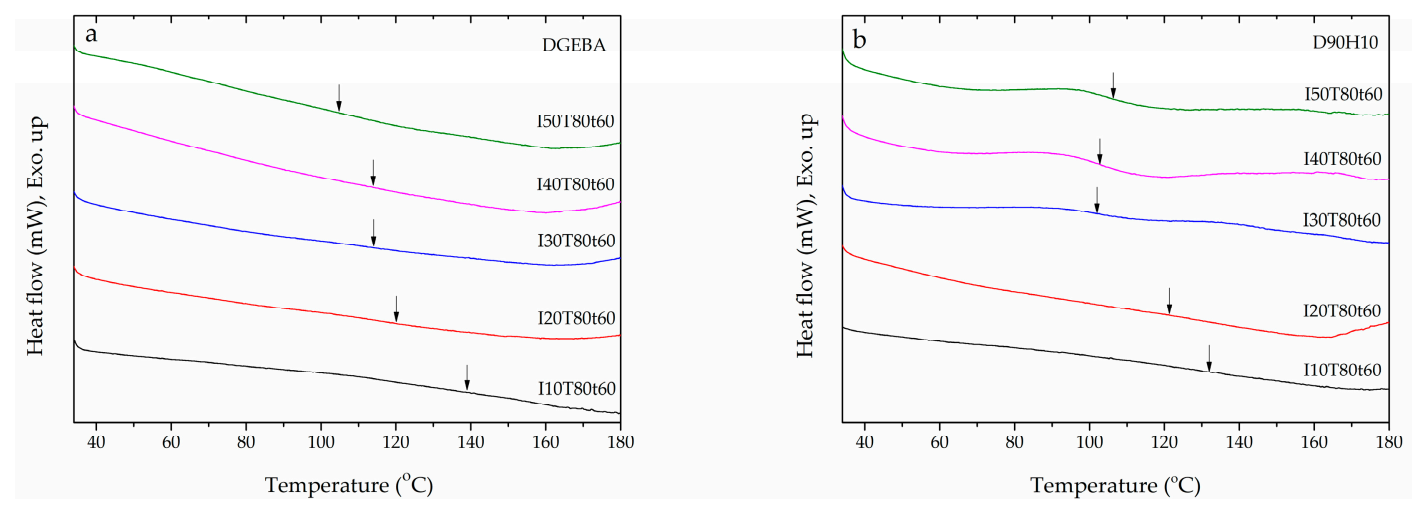

Figure 9. DSC thermograms showing glass transition temperature of (a) DGEBA and (b) D90H10 thermosets cured at various UV intensity.
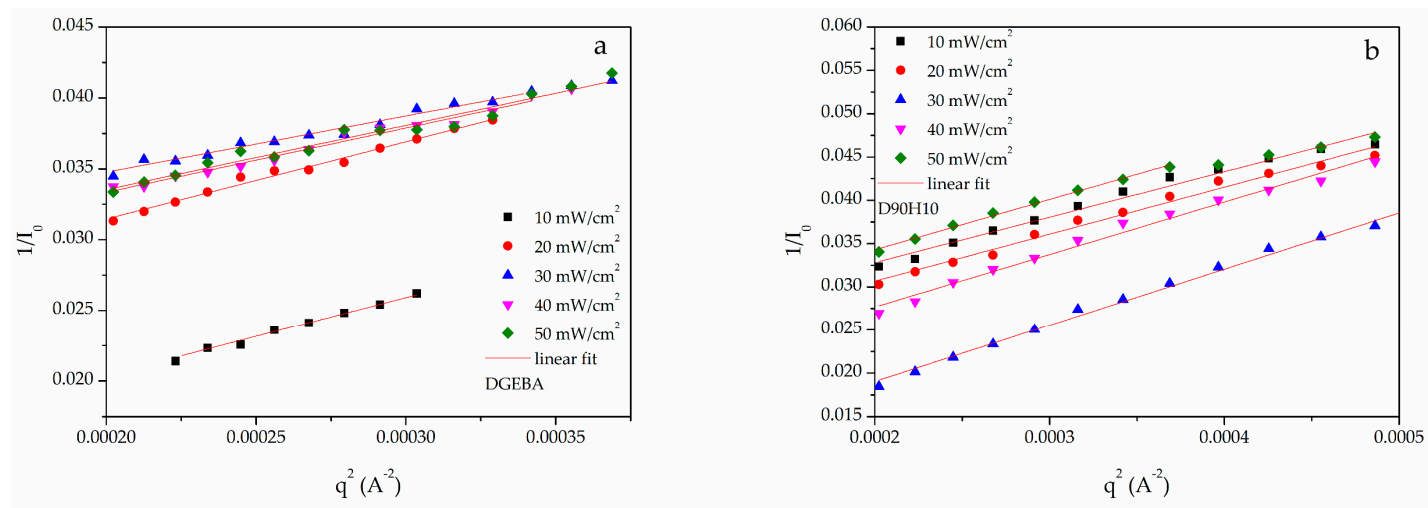

Figure 10. Zimm plot for (a) DGEBA and (b) D90H10 thermosets cured at various UV intensity.

As shown in Table 2, a relationship was found between $R_{\mathrm{g}}$ and $M_{\mathrm{c}}$, for each sample. As a result, when $M_{\mathrm{c}}$ increased for both the DGEBA and D90H10 systems, $R_{\mathrm{g}}$ increased. As regards the DGEBA system, when UV intensity increased, $R_{\mathrm{g}}$ decreased. The D90H10 system, however, did not follow the same trend because of the addition of the HBE10P resin. Again, when UV intensity increased from 10 to $30 \mathrm{~mW} / \mathrm{cm}^{2}, R_{\mathrm{g}}$ increased because there were more protonated epoxide molecules in HBE10P, and it could react with others to form large molecules between crosslinking points, which resulted in low cross-link density and low $T_{\mathrm{g}}$. Yet, when UV intensity increased from 30 to $50 \mathrm{~mW} / \mathrm{cm}^{2}, R_{\mathrm{g}}$ decreased because $M_{\mathrm{c}}$ greatly decreased. There were also many activated photoinitiator molecules and protonated epoxide molecules, generating a lot of active chains. Each active chain quickly encountered each other, and this resulted in very low $M_{\mathrm{c}}$, high cross-link density and high $T_{\mathrm{g}}$. Because of predomination of the internal plasticizer effect from PEG's structure in the HBE10P resin [21], $T_{\mathrm{g}}$ increased slightly. 


\section{Conclusions}

In this work, photo-DSC, photo-rheometer and SAXS measurements were used to investigate the occurrence of the epoxy systems during UV curing and the final properties of the cured samples. Through the relationship between curing behavior, rheological and thermal properties, the short gelation time led to an increase in UV conversion and cure rate. Moreover, the values of the molecular weight between the crosslinking points, radius of gyration of the network segment, and glass transition temperature were seen to be congruent. It was noted that the addition $10 \mathrm{wt} \%$ of HBE10P affected the characteristics of the DGEBA system. Thus, the ball-bearing effect and branching structure of the hyperbranched epoxy increased the mobility of the system resulting in the improvement of conversion and cure rate. As $T_{\mathrm{g}}$ decreased, the low impact resistance of the DGEBA thermoset was enhanced accordingly. After UV irradiation in the DSC thermogram, the AM mechanism exhibited a second exothermic peak. In conclusion, the glass transition temperature for both the DGEBA and D90H10 systems depends on the reaction mechanism, the structure of resins, and UV intensity.

Supplementary Materials: The following are available online at http://www.mdpi.com/2073-4360/12/10/2240/s1. Table S1: The density of each sample cured at various UV intensity. Table S2: Parameters from Zimm plot for DGEBA and D90H10 at various UV intensity. Figure S1 FTIR spectra of HBE10P resin. Figure S2 ${ }^{1} \mathrm{H}$ NMR spectrum of HBE10P resin. Figure S3: Crossover of storage modulus $\left(\mathrm{G}^{\prime}\right)$ and loss modulus ( $\left.\mathrm{G}^{\prime \prime}\right)$ of DGEBA system at various curing condition: (a) $10 \mathrm{~mW} / \mathrm{cm}^{2}$, (b) $20 \mathrm{~mW} / \mathrm{cm}^{2}$, (c) $30 \mathrm{~mW} / \mathrm{cm}^{2}$, (d) $40 \mathrm{~mW} / \mathrm{cm}^{2}$, and (e) $50 \mathrm{~mW} / \mathrm{cm}^{2}$. Figure S4: Crossover of storage modulus $\left(\mathrm{G}^{\prime}\right)$ and loss modulus $\left(\mathrm{G}^{\prime \prime}\right)$ of $\mathrm{D} 90 \mathrm{H} 10$ system at various curing condition: (a) $10 \mathrm{~mW} / \mathrm{cm}^{2}$, (b) $20 \mathrm{~mW} / \mathrm{cm}^{2}$, (c) $30 \mathrm{~mW} / \mathrm{cm}^{2}$, (d) $40 \mathrm{~mW} / \mathrm{cm}^{2}$, and (e) $50 \mathrm{~mW} / \mathrm{cm}^{2}$. Figure S5: SAXS profiles of (a) DGEBA and (b) D90H10 cured at various UV intensity. Figure S6 (a) Rheometer and (b) DSC instruments equipped with UV light guide.

Author Contributions: Conceptualization, T.B.-u. and A.S.; methodology, T.B.-u., K.T., and A.S.; investigation, T.B.-u., K.T., and A.S.; data curation, T.B.-u.; writing-original draft preparation, T.B.-u.; writing-review and editing, K.T. and A.S.; visualization, T.B.-u.; supervision, A.S. All authors have read and agreed to the published version of the manuscript.

Funding: This research was funded by the Research and Researchers for Industries (RRI): Thailand Research Fund (TRF), PHD57I0031.

Acknowledgments: The authors would like to thank the Research and Researchers for Industries (RRI): Thailand Research Fund (TRF) for financial support (PHD57I0031). The authors are also grateful to TAKI laboratory, Faculty of Mechanical Engineering, Institute of Science and Engineering, Kanazawa University, Japan for experimental and technical supports.

Conflicts of Interest: The authors declare no conflict of interest.

\section{References}

1. Golaz, B.; Michaud, V.; Leterrier, Y.; Månson, J.-A. UV intensity, temperature and dark-curing effects in cationic photo-polymerization of a cycloaliphatic epoxy resin. Polymer 2012, 53, 2038-2048. [CrossRef]

2. Moon, J.; Shul, Y.-G.; Han, H.; Hong, S.; Choi, Y.; Kim, H. A study on UV-curable adhesives for optical pick-up: I. Photo-initiator effects. Int. J. Adhes. Adhes. 2005, 25, 301-312. [CrossRef]

3. Crivello, J.V. UV and electron beam-induced cationic polymerization. Nucl. Instruments Methods Phys. Res. Sect. B Beam Interact. Mater. Atoms 1999, 151, 8-21. [CrossRef]

4. Decker, C. Photoinitiated crosslinking polymerisation. Prog. Polym. Sci. 1996, 21, 593-650. [CrossRef]

5. Decker, C.; Moussa, K. Kinetic study of the cationic photopolymerization of epoxy monomers. J. Polym. Sci. Part A: Polym. Chem. 1990, 28, 3429-3443. [CrossRef]

6. Vidil, T.; Tournilhac, F.; Musso, S.; Robisson, A.; Leibler, L. Control of reactions and network structures of epoxy thermosets. Prog. Polym. Sci. 2016, 62, 126-179. [CrossRef]

7. Penczek, S.; Kubisa, P.; Szymanski, R. Activated monomer propagation in cationic polymerizations. Makromol. Chemie. Macromol. Symp. 1986, 3, 203-220. [CrossRef]

8. Ficek, B.A.; Thiesen, A.M.; Scranton, A.B. Cationic photopolymerizations of thick polymer systems: Active center lifetime and mobility. Eur. Polym. J. 2008, 44, 98-105. [CrossRef] 
9. Kim, Y.C.; Hong, S.; Sun, H.; Kim, M.G.; Choi, K.; Cho, J.; Choi, H.R.; Koo, J.C.; Moon, H.; Byun, D.; et al. UV-curing kinetics and performance development of in situ curable 3D printing materials. Eur. Polym. J. 2017, 93, 140-147. [CrossRef]

10. Halley, P.J.; George, G.A. Chemorheology of Polymers; Cambridge University Press (CUP): Cambridge, UK, 2009.

11. Taki, K.; Nakamura, T.; Taki, K.; Tomomi, N. Effects of Curing Conditions and Formulations on Residual Monomer Contents and Temperature Increase of a Model UV Gel Nail Formulation. J. Cosmet. Dermatol. Sci. Appl. 2011, 1, 111-118. [CrossRef]

12. Decker, C. UV-Radiation Curing of Adhesives. In Handbook of Adhesives and Surface Preparation; Elsevier BV: Amsterdam, The Netherlands, 2011; pp. 221-243.

13. Peeters, S. Overview of dual-cure and hybrid-cure systems in radiation curing. In Radiation Curing in Polymer Science and Technology; Fouassier, J.P., Rabek, J.F., Eds.; Springer Science \& Business Media: Berlin, Germany, 1993; Volume 3, pp. 177-217.

14. Kotch, T.G.; Lees, A.J.; Fuerniss, S.J.; Papathomas, K.I. Luminescent organometallic complexes as visible probes in the isothermal curing of epoxy resins. Chem. Mater. 1992, 4, 675-683. [CrossRef]

15. Yu, J.; Huang, X.; Wang, L.; Peng, P.; Wu, C.; Wu, X.; Jiang, P. Preparation of hyperbranched aromatic polyamide grafted nanoparticles for thermal properties reinforcement of epoxy composites. Polym. Chem. 2011, 2, 1380. [CrossRef]

16. Guo, Q.; Harrats, C.; Groeninckx, G.; Koch, M. Miscibility, crystallization kinetics and real-time small-angle $\mathrm{X}$-ray scattering investigation of the semicrystalline morphology in thermosetting polymer blends of epoxy resin and poly(ethylene oxide). Polymer 2001, 42, 4127-4140. [CrossRef]

17. Horng, T.J.; Woo, E.M. Effects of network segment structure on the phase homogeneity of crosslinked poly (ethylene oxide)/epoxy networks. Polymer 1998, 39, 4115-4122. [CrossRef]

18. Kalogeras, I.M.; Roussos, M.; Christakis, I.; Spanoudaki, A.; Pietkiewicz, D.; Brostow, W.; Vassilikou-Dova, A. Dielectric properties of cured epoxy resin+poly(ethylene oxide) blends. J. Non Crystalline Solids 2005, 351, 2728-2734. [CrossRef]

19. Luo, X.; Zheng, S.; Zhang, N.; Ma, D. Miscibility of epoxy resins/poly(ethylene oxide) blends cured with phthalic anhydride. Polymer 1994, 35, 2619-2623. [CrossRef]

20. Gong, W.; Mai, Y.; Zhou, Y.; Qi, N.; Wang, B.; Yan, D. Effect of the Degree of Branching on Atomic-Scale Free Volume in Hyperbranched Poly[3-ethyl-3-(hydroxymethyl)oxetane]. A Positron Study. Macromolecules 2005, 38, 9644-9649. [CrossRef]

21. Boonlert-Uthai, T.; Samthong, C.; Somwangthanaroj, A. Synthesis, Thermal Properties and Curing Kinetics of Hyperbranched BPA/PEG Epoxy Resin. Polymer 2019, 11, 1545. [CrossRef]

22. Sixun, Z. Epoxy resin/poly(ethylene oxide) blends cured with aromatic amine. Polymer 1995, 36, 3609-3613. [CrossRef]

23. ASTM D1652-97. Standard Test Methods for Epoxy Content of Epoxy Resins; ASTM International: West Conshohocken, PA, USA, 1997.

24. Hammouda, B. A Tutorial on Small-Angle Neutron Scattering from Polymers; National Institute of Standards and Technology: Gaithersburg, MD, USA, 1995.

25. Rubinstein, M. Polymer physics-The ugly duckling story: Will polymer physics ever become a part of "proper" physics? J. Polym. Sci. Part B: Polym. Phys. 2010, 48, 2548-2551. [CrossRef]

26. Ganjaee-Sari, M.; Stribeck, A.; Moradian, S.; Zeinolebadi, A.; Bastani, S.; Botta, S.; Bakhshandeh, E. Dynamic mechanical behavior and nanostructure morphology of hyperbranched-modified polypropylene blends. Polym. Int. 2013, 63, 195-205. [CrossRef]

27. Jafarifard, S.; Bastani, S.; Soleimani-Gorgani, A.; Ganjaee-Sari, M. The chemo-rheological behavior of an acrylic based UV-curable inkjet ink: Effect of surface chemistry for hyperbranched polymers. Prog. Org. Coat. 2016, 90, 399-406. [CrossRef]

28. Ganjaee-Sari, M.; Moradian, S.; Bastani, S.; Stribeck, N. Modification of poly(propylene) by grafted polyester-amide-based dendritic nanostructures with the aim of improving its dyeability. J. Appl. Polym. Sci. 2011, 124, 2449-2462. [CrossRef]

29. Luo, X.; Xie, S.; Liu, J.; Hu, H.; Jiang, J.; Huang, W.; Gao, H.; Zhou, D.; Lu, Z.; Yan, D. The relationship between the degree of branching and glass transition temperature of branched polyethylene: Experiment and simulation. Polym. Chem. 2014, 5, 1305-1312. [CrossRef] 
30. Luo, X.; Xie, S.-J.; Huang, W.; Dai, B.-N.; Lu, Z.; Yan, D.-Y. Effect of branching architecture on glass transition behavior of hyperbranched copolystyrenes: The experiment and simulation studies. Chin. J. Polym. Sci. 2015, 34, 77-87. [CrossRef]

31. Shi, Y.; Cao, X.; Luo, S.; Wang, X.; Graff, R.W.; Hu, D.; Guo, R.; Gao, H. Investigate the Glass Transition Temperature of Hyperbranched Copolymers with Segmented Monomer Sequence. Macromolecules 2016, 49, 4416-4422. [CrossRef]

32. Pongsa, U.; Samthong, C.; Somwangthanaroj, A. Direct functionalization with 3,5-substituted benzoic acids of multiwalled carbon nanotube/epoxy composites. Polym. Eng. Sci. 2013, 53, 2194-2204. [CrossRef]

33. Pongsa, U.; Somwangthanaroj, A. Effective thermal conductivity of 3,5-diaminobenzoyl-functionalized multiwalled carbon nanotubes/epoxy composites. J. Appl. Polym. Sci. 2013, 130, 3184-3196. [CrossRef]

34. Boey, F.Y.C.; Qiang, W. Glass-transition temperature-conversion relationship for an epoxy-hexahydro-4methylphthalic anhydride system. J. Appl. Polym. Sci. 2000, 78, 511-516. [CrossRef]

35. Rath, S.; Boey, F.; Abadie, M. Cationic electron-beam curing of a high-functionality epoxy: Effect of post-curing on glass transition and conversion. Polym. Int. 2004, 53, 857-862. [CrossRef]

(C) 2020 by the authors. Licensee MDPI, Basel, Switzerland. This article is an open access article distributed under the terms and conditions of the Creative Commons Attribution (CC BY) license (http://creativecommons.org/licenses/by/4.0/). 